\title{
An overview on polysulphone/clay nanocomposites
}

\begin{abstract}
Polymer clay nanocomposites have become a distinct field of existing research and development in the last few decades due to its magnificent properties as well as its general amazing behavior. The progress in developments on the use of modified natural and synthetic clays for designing polymer nanocomposites have dominated the polymer literature, due to their potential for improvement chemical, physical, electrical, thermal and mechanical properties compared to conventionally filled composites. This review aims to provide a description of the recent advances in the preparation of polymer clay nanocomposites and their enhanced properties and morphologies. Also, other related fields that include the types, structures and modification methods of clay.
\end{abstract}

Keywords: clay, polysulphone, nanocomposites, chemical modifications
Volume 3 Issue I - 2017

\author{
Mahmoud A Hussein, ${ }^{1,3}$ Abdelaal MY, ${ }^{1,2}$ Abeer \\ MAlosaimi,' Tariq R Sobahi' \\ 'Chemistry Department, King Abdulaziz University, Saudi Arabia \\ ${ }^{2}$ Chemistry Department, Mansoura University, Egypt \\ ${ }^{3}$ Chemistry Department, Assiut University, Egypt
}

Correspondence: Mahmoud A Hussein, Chemistry Department, Faculty of Science, King Abdulaziz University, PO Box 80203, Jeddah 21589, Saudi Arabia,

Email mahussein74@yahoo.com, maabdo@kau.edu.sa

Received: May 21, 2017 | Published: July 20, 2017

\section{Introduction}

In recent years, polymer-clay composite is an important class of materials and has attracted great attention, either in industry or in academia, because they often show remarkable improvement in materials properties such as when layered silicates are entered as a filler in the polymer matrix with very small volume fractions. ${ }^{1}$ Advantage of using low amount of filler can also be said to retain the optical clarity as well as low density of the formed composite materials. The nanocomposite technology has featured a great enhancement in the structural and functional properties of synthetic polymers. ${ }^{2}$ Several studies on polymer nanocomposites have reported such improvements including, for instance, tensile strength, thermal stability, decreased gas permeability, decreased ionic conductivity and increased heat and flame resistance. ${ }^{3}$ These materials have the power and high efficiency on the performance in many areas of the industry for low cost commercial applications. For the efficiency of these materials, there was great interest in preparing them and studying their properties. ${ }^{4,5}$ In the early, Toyota research group demonstrated the distinguished improvement in the material properties of an exfoliated Nylon-6/ clay nanocomposite. Various polymers have been used in many applications through massive studies around the world and reflected by the rapid increasing citation in recent years. ${ }^{6}$ These include, but are not limited to, polyurethane, polypropylene, polystyrene, polyimides, poly(ethylene oxide), polyethylene, polycaprolactone, polyamides, poly(ethylene terephthalate), polycarbonate, and epoxy resins. ${ }^{7}$

Today, efforts are being conducted globally, using almost all types of polymers as matrices in nanocomposite formation. So, the field of polymer-clay nanocomposites has recently gained momentum. Recently viewed citations on polymer-clay nanocomposites have rapidly increased in recent years. Also, the surface modification has become increasingly important to improve the practical applications of such materials. One of the most effective methods is the surface modification of polymers as the surface properties of variety of functional polymers can be widely changed. The surface modification through the variation of clay is a distinctive part for several researchers. ${ }^{8,9}$ This review illustrates the major developments in this area during the last decade including the types of mineral silicates and different techniques used to prepare polymer-clay nanocomposites, their morphologies, their improved properties, modifying methods and potential applications.

\section{Clay}

Clay has been known and used for very long time and recently became an indispensable part of our modern life, as used in the form of porcelain, tiles, bricks and sanitary ware and as an essential constituent of plastics, rubber, paints, cosmetics, paper, and medicine. ${ }^{10,11}$ Among all types of filler, clays are naturally abundant, economical, and benign to the environment. The term "clay" refers to a fine-grained natural rock or soil material made up of layered silicates or clay minerals with traces of metal oxides and organic matter. Clay minerals have crystalline form and they are hydrous aluminum phyllosilicates, sometimes with variable amounts of metals such as iron, magnesium, lithium, alkali metals, alkaline earths, and other cations. ${ }^{12}$

\section{Classification of clay}

In general, clay has two main types, namely, natural and synthetic clays. Depending on the academic source, clay can be divided into three main categories and many subcategories as shown in Figure 1. If there is only one tetrahedral group and one octahedral group in each layer, the clay is known as 1:1 clay e.g. Kaolinite and 2:1 clay has one octahedral sheet between two tetrahedral sheets. The 2:1 layer silicates include some types like mica, smectite, vermiculite and chlorite. Also, smectite group is divided into montmorillonite (MMT), nontronite, saponite and hectorite $\operatorname{species}^{13}$ (Figure 1).

\section{Structure and properties of clay}

Clay contains $\mathrm{SiO}_{4}$ as a basic chemical unit and the silicon ion is a central ion and has a charge of $(+4)$ while each oxygen has a charge of (-2). Thus, each silicon-oxygen bond has one half of the total bond energy of oxygen, so, there is a tetrahedron shaped anionic group with a charge of (-4). This situation leaves the oxygen with the option of bonding to another silicon ion and, therefore, linking one $\mathrm{SiO}_{4}$ tetrahedron to another and so forth. ${ }^{12}$ Phyllosilicates (2:1 layered) are the most generally used from other clay types for the preparation of polymer nanocomposites. MMT is the most commonly used for fabrication of polymer nanocomposites because it is highly abundant and it has high-surface area that could lead to materials of a great improved properties. ${ }^{14,15}$ In addition, it is environmentally friendly, naturally occurring and inexpensive with the chemical formula shown in Figure 2. ${ }^{12}$ The MMT crystal structure consists of a layer of octahedral aluminum hydroxide sheet sandwiched between two layers 
of tetrahedral silicon oxide sheets. The layer thickness of each platelet is equal to $1 \mathrm{~nm}$, and the lateral dimension is approximately $200 \mathrm{~nm}$. These clay platelets are piled up on each other and bonded together by Van der Waal forces. The separation space between each other is $1 \mathrm{~nm}$ gaps (galleries). These galleries are usually occupied by cation ions, such as $\mathrm{Na}^{+}, \mathrm{Li}^{+}$and $\mathrm{K}^{+}$that make balance with the negative charges generated from isomorphic substitution within the layers (for montmorillonite, $\mathrm{Al}^{3+}$ replaced by $\left.\mathrm{Mg}^{2+}\right) .{ }^{16}$ Generally, layered silicates have two specific characteristics that are very important for polymer clay nanocomposite production. The first is the ability of the silicate particles to disperse within individual polymer layers. The second characteristic is the surface ability toward ion exchange reactions with organic and inorganic cations. These two characteristics are associated together because the dispersion degree of layered silicate in a particular polymer matrix depends on the interlayer cations ${ }^{17}$ (Figure 2).

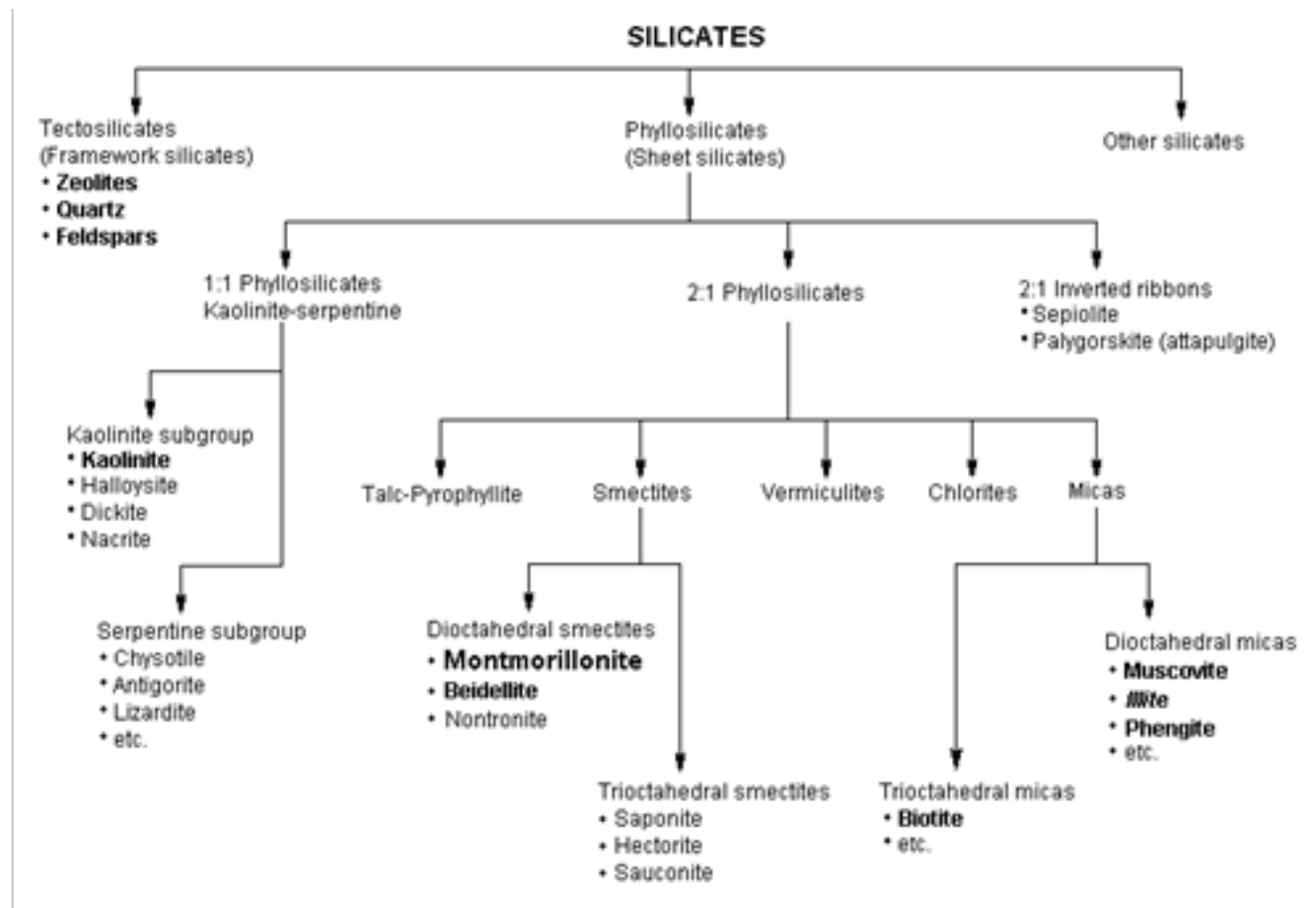

Figure I Main categories and subcategories of silicates.

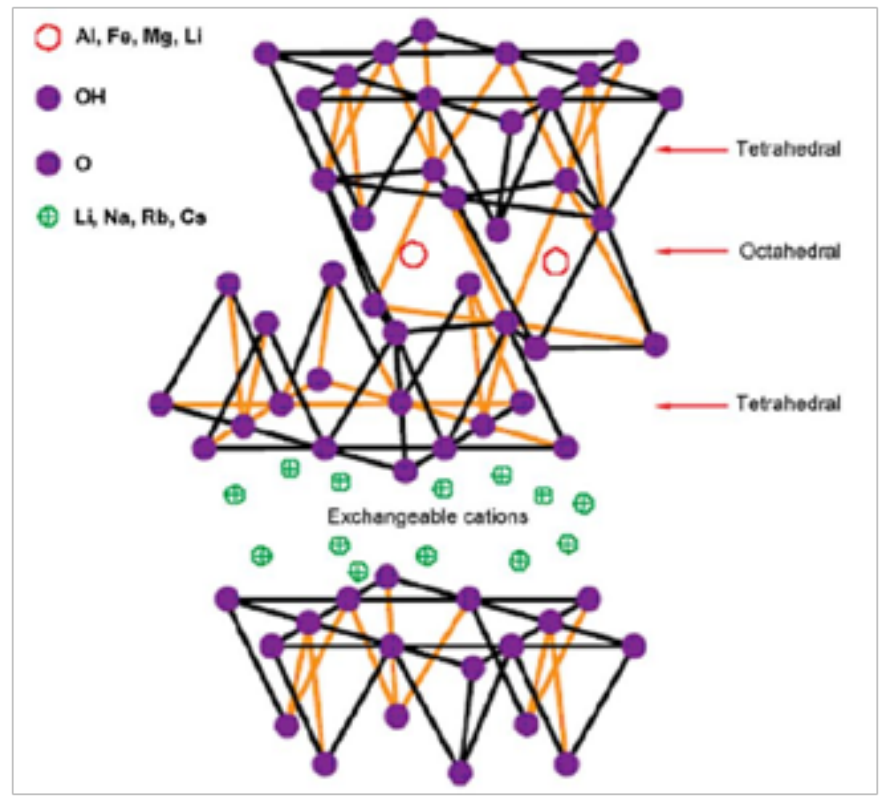

Figure 2 Unit crystal structure of montmorillonite.

\section{Structure and properties of organoclay}

Clays in their nature are hydrophilic while most polymers are usually hydrophobic. Therefore, due to the fundamental incompatibility of hydrophilic-layered silicates and hydrophobic polymers, the dispersion of silicates in polymer matrix is not easy method. ${ }^{13}$ Through ion-exchange reactions, inorganic ions in the clay interlayer can be effectively replaced by organic cationic surfactant molecules. ${ }^{12}$ The result of this processing is expansion of the interlayer spacing which leads to an increase in the basal spacing. Therefore, more significant improved properties such as wettability and thermodynamic interactions can be achieved for the purpose of medical and industrial applications through chemical modification of clay. ${ }^{18}$ Generally, this can be performed by ion-exchange reactions with cationic surfactants including primary, secondary, tertiary, and quaternary alkyl ammonium or alkylphosphonium cations. This ion-exchange reaction leads to the formation of an organophilic clay. An alkyl- ammonium or phosphonium salt is added to that aqueous dispersion, then, the surfactant ions are exchanged with the intergallery cations. The cations are intercalated between the layers and the intergallery height increases. ${ }^{16,19}$ The modification of the clay surface can be achieved and the hydrophilicity, hydrophobicity and other properties of the clay can be adjusted by changing the length or type of alkyl chain or adding some polar groups in the surfactant salt. $^{20,21}$

\section{Polymer/Clay nanocomposites}

\section{Polymer/clay nanocomposite morphology}

The related between performance of nanocomposites to their morphological structure is an important case. Based on the strength 
of interfacial interaction between the clay and the polymer matrix, the morphologies of polymer clay composites have three main types: intercalated, flocculated and exfoliated. Transmission electron micrographs of different representative microstructures of a polymer-clay nanocomposite systems are shown in Figure $3 .^{22}$ In the intercalated nanocomposites, the insertion of a polymer matrix into the layered silicate structure occurs in a crystallographically regular way, via alternating polymer chains and silicate layer. In the exfoliated nanocomposites, the individual clay layers are randomly separated in a continuous polymer matrix by an average distance that depends on the clay loading ${ }^{23}$ (Figure 3).
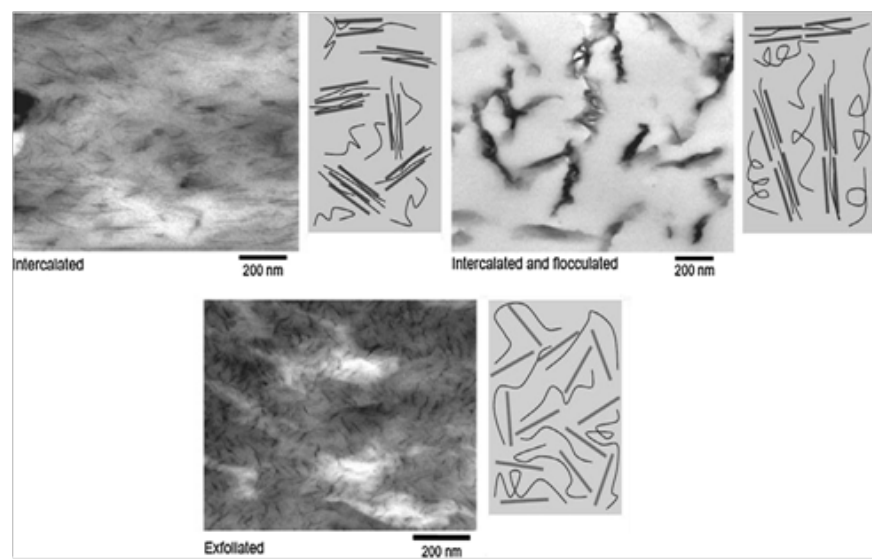

Figure 3 Transmission electron microscopic images of three different types of polymer-clay nanocomposites.

\section{Clay and polymer modification for nanocomposite formation}

The poor physical interaction between polymer and clay leads to poor mechanical and thermal properties. To overcome this drawback, the modification of the materials and the modification process of nanocomposite formation need to be modified. Generally, there are two common techniques to improve the dispersion of different clays within the polymer matrix, namely, the use of a compatibilizer and clay organophilization. Frequently, a compatibilizer can be a polymer which is chemically compatible with both of the clay and the matrix. Such chemical compatibility can be provided by chemical treatment such as grafting of reactive groups or copolymerization with another polymer containing reactive groups. Clay organophilization aims at a better interaction of the clay with the polymer through the exchange of interlamellar cations (generally, sodium and calcium ions) with positively charged organic molecules. This neutralizes the negative charges of the silicate layers and the clay will be converted to an organophilic clay. Generally, amino acids, alkylammonium and other salts of this family are used to improve clay wettability by the polymer matrix and to facilitate the penetration of the organic molecules between their platelets. ${ }^{10,13}$ Figure 4 illustrates the ion exchange process and modification of clay layers using cations salt. ${ }^{8,24,25}$ (Figure $4)$.

\section{Polymer/clay nanocomposite preparation}

In general, the methods used in the preparation of nanocomposite can be divided into four processing techniques. The first developed method is in-situ polymerization in which a monomer solution is used as a medium for the clay dispersion and favorable conditions are performed to allow the polymerization to occur between the clay mineral layers. Polymerization can be initiated by heat or radiation after diffusion of a suitable and enough initiator or a fixed catalyst inside the clay layers before the filling step with the monomer. Since the clay mineral has high surface energy, so the clay mineral layers can attract monomer units inside the galleries until equilibrium is reached. Complete exfoliation occurs since the driving force for complete exfoliation is polymerization which occurs between the layers of lower polarities. ${ }^{10,26}$

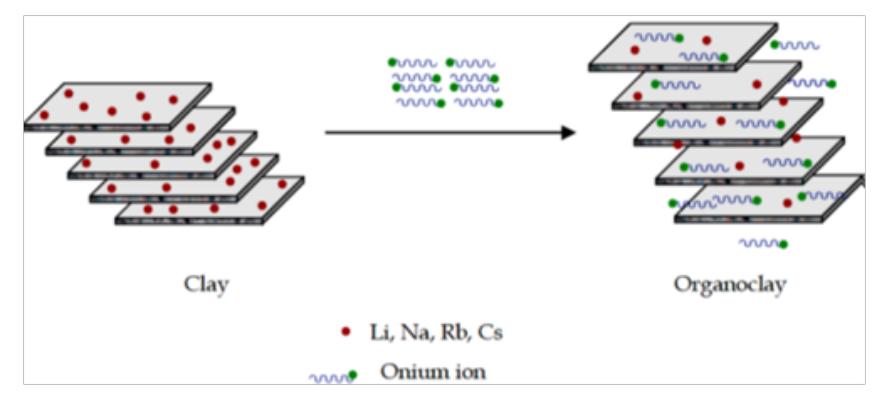

Figure 4 Modification of clay layers by organic onium cations.

The second method is the solution mixing or solvent casting in which silicate is exfoliated in single layers within the solvent system. The polymer or pre-polymer is dissolved in a solvent such as water, chloroform, or toluene and silicates can be easily dispersed in a suitable solvent through the entropy increase caused by the disorganization of the layers. ${ }^{10}$ The polymer intercalates in the silicate layers and after the solvent is evaporated or the mixture is precipitated, the layers filled with polymer are reunited. In the best case, an intercalated morphology or multilayer structure usually is the required..$^{27}$ The third method is the melt intercalation method in which the molten polymer matrix is mixed with the silicate layers. During the heating process, the molten polymer chains diffuse into the silicate galleries to form either an intercalated or exfoliated nanocomposite. This technique is simple and environmentally friendly and doesn't need solvent. ${ }^{10}$ Finally, the fourth method consists of suspension of the clay in water or solvent to increase its base spacing followed by mixing directly with the polymer. This leads to intercalation of the polymer matrix in the increased basal spacing. ${ }^{6,11}$

\section{Characterization techniques for polymer/clay nanocomposites}

There are some techniques to characterize the polymer/clay nanocomposites such as the degree of exfoliation and the interlayer spacing. The mostly used methods to typically characterize the nanocomposite structure are Wide Angle X-ray Diffraction (WAXD) analysis and Transmission Electron Microscopy (TEM). WAXD can be used to identify the structure of intercalated or exfoliated nanocomposites by monitoring the position, shape, and intensity of the basal reflections from the distributed silicate layers. In other words, WAXD can be considered a suitable method to determine the interlayer spacing of the silicate layers either in the original layered silicates or in the intercalated nanocomposites while the spatial distribution of the silicate layers is not easy. TEM allows understanding the internal structure and the spatial distribution of various phases and shows the structure defect through direct visualization. Together, TEM and WAXD are essential techniques for determining nanocomposite structure. ${ }^{1,6}$

\section{Application}

The incorporation of nanoclay in the polymer matrix is advantageous and may lead to plenty of application areas including 
membrane separation, UV screens, flammability resistance, barrier properties, polymer blend compatibilization, impact modification, electrical conductivity and biomedical applications. The exfoliated clay-modified polyethylene terephthalate (PET) is one of the common nanocomposites investigated by both academic and industrial laboratories for barrier applications. PET-exfoliated clay composites prepared by in-situ polymerization showed a 2 -fold reduction in permeability with the use of $1 \mathrm{wt}$. \% clay only compared to the control PET while they did not show any significant change in the moisture vapor transmission. Poly (methyl methacrylate) (PMMA)/ clay nanocomposites were prepared also via in-situ polymerization and were used to improve ionic conductivity and for gas storage and packaging applications as demonstrated by high barrier polymerclay films. In another example, exfoliation of polyamide 6/polyolefin clay yielded nanocomposites with improved barrier properties to styrene permeation for melt blown films relative to the polyamide nanocomposite. ${ }^{3}$

The polymer-clay nanocomposites have been used in mechanical and thermal reinforcement of thermoplastics such as polyamide- 6 and polypropylene. Polyamide-6/ clay nanocomposite produced by Ube/ Toyota was used to replace a metal component which yielded some weight savings. Incorporation of clay in the polymer nanocomposites application improved the heat distortion temperature of the material allowing the application at higher temperature. ${ }^{28}$ Table 1 contains some examples of commercial polymer-based nanocomposites ${ }^{3,29,30}$ (Table 1). Generally, the field of polymer/clay nanocomposites is creating new materials which have likely been in use already for quite some time. However, there is a progress in chemistry and material science and thus the growth in number and capability of new products and applications used this technology is not surprising.

Table I Examples of nanocomposite commercial utility

\begin{tabular}{|c|c|c|c|c|}
\hline Polymer matrix & Nanoparticle & Property improvement & Application & $\begin{array}{l}\text { Company and/or } \\
\text { product trade name }\end{array}$ \\
\hline Polyamide 6 & Exfoliated clay & Stiffness & Timing belt cover: automotive & Toyota/Ube \\
\hline Thermoplastic polyolefin & Exfoliated clay & Stiffness/Strength & Exterior step assist & General motors \\
\hline Polyisobutylene & Exfoliated clay & Permeability barrier & Tennis Balls, Tires, Soccer Balls & InMat LLC \\
\hline Polyamides nylon $6,66,12$ & Exfoliated clay & Barrier & Auto fuel systems & Ube \\
\hline Polysulfone & Halloysite Clay and Copper Ion & Strength & Ultrafiltration membrane & \\
\hline Epoxy & Clay (Intercalation/Exfoliation) & $\begin{array}{l}\text { Mechanical, Thermal and } \\
\text { Barrier properties }\end{array}$ & Aerospace, Defense, Automobile & \\
\hline Polyurethne & Clay & Interfacial interactions & Automotive & \\
\hline
\end{tabular}

\section{Conclusion}

During formulation of polymer/clay nanocomposites, incorporation of a low percentage of clay improves remarkably the mechanical, thermal, electrical, interfacial adhesion and barrier properties, etc., especially when compared with the conventional composites. Also, the nano-level dispersion of silicate particles is the most important characteristic for the increased interfacial adhesion or surface area for polymer clay interaction to be achieved. Modification process of the clay and their effects on the structure and properties of polymer nanocomposites have been clarified in this review. Using the ionexchange chemistry to decrease the inherent Van der Waals forces among silicate layers and to improve the delamination of silicate platelets in polymer matrices is also covered. Moreover, the processing method and the application of polymer/clay nanocomposites were mentioned.

\section{Acknowledgements}

None.

\section{Conflict of interest}

The author declares no conflict of interest.

\section{References}

1. Wang J, Mao Q. A novel process control methodology based on the PVT behavior of polymer for injection molding. Advances in Polymer Technology. 2013;32(S1):E474-E485.

2. Pavlidou S, Papaspyrides CD. A review on polymer-layered silicate nanocomposites. Progress in Polymer Science. 2008;33:1119-1198.
3. Paul DR, Robeson LM. Polymer nanotechnology : Nanocomposites. Polymer. 2008;49(15):3187-3204.

4. Yin Y, Talapin D. The chemistry of functional nanomaterials. Chemical Society Reviews. 2013;42(7):2484-2487.

5. Chung DDL. 4 - Polymer-Matrix Composites: Mechanical Properties and Thermal Performance, in Carbon Composites. 2nd ed. UK: Butterworth-Heinemann; 2017. p. 218-255.

6. Hussain F, Hojjati M, Okamoto M, et al. Gorga review article: polymermatrix nanocomposites, processing, manufacturing and application: an overview. Journal of Composite Materials. 2006;40(17):27-32.

7. Devices M. 8 High-temperature engineering thermoplastics:liquid crystalline polymers, and fluoropolymers; 2014. p. 173-213.

8. Liu P. Polymer modified clay minerals: A review. Applied Clay Science. 2007;38:64-76.

9. Burgos-Mármol JJ, Patti A. Unveiling the impact of nanoparticle size dispersity on the behavior of polymer nanocomposites/citation formates. Polymer. 2017;113:92-104.

10. Vlack V. Clay-containing polysulfone nanocomposites; 2006.

11. Okada A, Usuki A. Twenty years of polymer-clay nanocomposites. Macromolecular Materials and Engineering. 2006;291(12):1449-1476.

12. Sinha Ray S. An overview of pure and organically modified clays. Claycontaining Polymer Nanocomposites. 2003. p. 1-24.

13. Kotal M, Bhowmick AK. Polymer nanocomposites from modified clays: recent advances and challenges. Progress in Polymer Science. 2015;51:127-187.

14. Anadão P, Sato L Fumie, Wiebeck H, et al. Montmorillonite as a component of polysulfone nanocomposite membranes. Applied Clay Science. 2010;48(1-2):127-132. 
15. Monticelli O, Aldo B, Scandale I, et al. Preparation and properties of polysulfone-clay composite membranes. Wiley Inter Science. 2006;103:3637-3644.

16. Bhattacharya SS, Aadhar M. Studies on preparation and analysis of organoclay nano particles. Research Journal of Engineering Science. 2014;3(3):10-16.

17. Sinha Ray S, Okamoto M. Polymer/layered silicate nanocomposites: A review from preparation to processing. Progress in Polymer Science. 2003;28:1539-1641.

18. Singla P. Organic modification of clay. Sci Res. 2009. p. 21-25.

19. Singla P, Mehta R, Upadhyay SN. Clay modification by the use of organic cations. Green and Sustainable Chemistry. 2012;2(1):21-25.

20. Hoidy WH, Ahmad MB, Ahmad AJAM, et al. Synthesis and characterization of organoclay from sodium montmorillonite and fatty hydroxamic acids. American Journal of Applied Sciences. 2009;6(8):1567-1572.

21. Paiva De LB, Morales AR, Valenzuela Díaz FR. Organoclays: Properties, preparation and applications. Applied Clay Science. 2008;42:8-24.

22. Delogu F, Gorrasi G, Sorrentino A. Fabrication of polymer nanocomposites via ball milling: Present status and future perspectives. Progress in Materials Science. 2017;86:75-126.

23. Passador FR, Ruvolo Filho A, Pessan LA, et al. 7 - Nanocomposites of polymer matrices and lamellar clays A2 - Róz in Nanostructures. USA: William Andrew Publishing; 2017. p. 187-207.
24. Bahari A, Ashrafi F, Babenejad A, et al. Investigation and characterization of Nano clay structures. Archives of Applied Science Research. 2011;3(3):462-469.

25. Azzam WR. Behavior of modified clay microstructure using polymer nanocomposites technique. Alexandria Engineering Journal. 2014;53(1):143-150.

26. Bhattacharya M. Polymer nanocomposites-A comparison between carbon nanotubes, graphene, and clay as nanofillers. Materials. 2016;9(4):262.

27. Usuki A, Hasegawa N, Makoto K, et al. Polymer-clay nanocomposites. Inorganic Polymeric Nanocomposites and Membranes. 2005;179:135195

28. Anadão P. Polymer/ clay nanocomposites: concepts, researches, applications and trends for the future. In Nanocomposites - New Trends and Developments. 2012;51:953-978.

29. Karina AH, Javier I, María Del C Díaz-Nava, et al. Polymer-clay nanocomposites and composites: structures, characteristics, and their applications in the removal of organic compounds of environmental interest. Med chem (Los Angeles). 2016;6:201-210.

30. Azeez AA. Epoxy clay nanocomposites - processing, properties and applications: A review. Composites Part B: Engineering. 2013;45(1):308-320. 